\title{
APLICAÇÃO DAS TEORIAS DE INTERNACIONALIZAÇÃO EM PEQUENAS EMPRESAS
}

\section{APPLICATION OF INTERNATIONALIZATION THEORIES IN SMALL BUSINESS}

\author{
Roberta Manfron de Paula \\ Doutora em Administração pelo Programa de Pós-Graduação em Administração da Universidade Nove de Julho \\ Coordenadora de Curso - UNA Pouso Alegre \\ Pouso Alegre, MG, BRASIL \\ E-mail: roberta.manfron@gmail.com \\ Manuel Portugal Ferreira \\ Professor titular de estratégia no Programa de Pós-Graduação em Administração da Universidade Nove de Julho \\ São Paulo, SP, BRASIL \\ E-mail: manuel.portugal.ferreira@gmail.com \\ Paula da Silva Quinte Resende \\ Pós-Graduada em Planejamento e Gestão Estratégica - UNINTER e Bacharel em Administração pela Universidade do Vale do Sapucaí \\ Pouso Alegre, MG, BRASIL \\ E-mail: paula.squinte@gmail.com
}

\section{RESUMO}

Este estudo tem como principal objetivo analisar as estratégias de internacionalização de empresas, com uma aplicação a Prática Produtos S/A. Examinamos especificamente a trajetória deste caso até a entrada no mercado internacional e a utilização da inovação como fator competitivo na internacionalização. Pautado por uma pesquisa bibliográfica seguida de pesquisa aplicada exploratória descritiva por meio de entrevistas semiestruturadas com os gestores da empresa, observa-se pelos resultados da pesquisa que a empresa Prática Produtos S/A, através de elementos importantes como planejamento, inovação e qualificação profissional possui uma estrutura apta a enfrentar o mercado internacional. A contribuição deste estudo se caracteriza por retratar as iniciativas das pequenas empresas em ampliar suas atividades comerciais por meio da internacionalização, servindo assim como recurso orientador para outras empresas de pequeno porte desenvolver estratégias semelhantes.

Palavras-chave: Internacionalização. Prática Produtos S/A. Inovação. Pequenas Empresas. Setor Industrial.

\section{ABSTRACT}

This study aims to analyze the business internationalization strategies as an agent to promote organizational expansion of Practice Products $S$ / A, as well as check their track record to enter the international market and the use of innovation as a competitive factor in this process. Guided by an exploratory literature followed by research applied research descriptive through semi-structured interviews with company managers, there is the search results that the company Practice Products S / A through the important elements such as planning, innovation and professional training has an apt structure to face the international market. The contribution of this study is characterized by portraying the small business initiatives to expand its business activities through internationalization, thus serving as a guiding resource for other small businesses develop similar strategies.

Keywords: Internationalization. Practical Products S/A. Innovation. Small Business. Industrial Sector.

Data de aprovação: 28 de novembro de 2018. 


\section{INTRODUÇÃO}

Nas últimas décadas assistiu-se a maior internacionalização e entrada de empresas de economias emergentes (que designamos usualmente por multinacionais emergentes) nos mercados internacionais. A internacionalização das multinacionais emergentes tem combinado elementos de uma estratégia ou resposta passiva - ou seja, por efeito da concorrência de empresas estrangeiras no seu mercado doméstico ou em resposta a encomendas esporádicas - com a busca ativa por novos mercados para escoar produção e, também, com uma estratégia ativa de busca por upgrade tecnológico (STAL, 2010; BUCKLEY, CASSON, 2009; LE BAS, SIERRA, 2002; SZAPIRO, ANDRADE, 2001; BARTLETT; GHOSHALL, 2000). Alguns casos de internacionalização incluem, por exemplo, do Brasil, empresas como a Embraer, Vale, Petrobras, Marcopolo, Companhia Siderúrgica Nacional, Gerdau, Usiminas, Votorantim, Weg, Odebrecht e Natura, entre várias outras. Embora a evidência de casos de grande sucesso seja amplamente reconhecida, tem sido menos evidente o reconhecimento de quais os fatores, ou quais as fontes de vantagem competitiva que as multinacionais emergentes, por exemplo as Brasileiras, têm alavancado para competir no exterior com as empresas locais. Também ainda pouco entendido é o processo de internacionalização das multinacionais emergentes, inclusive se seguem o padrão gradual proposto pela escola de Upsalla (JOHANSON; VAHLNE, 1977), e as competências específicas construídas domesticamente que são alavancadas para as operações internacionais.

A internacionalização de empresas de economias emergentes se intensificou nas últimas três décadas (FERREIRA et al., 2011a; GOMES et al., 2010), mas a pesquisa tem estado focada em cenários organizacionais de empresas de grande porte (STAL, 2010; LE BAS, SIERRA, 2002; SZAPIRO, ANDRADE, 2001; BARTLETT; GHOSHALL, 2000), sendo consideravelmente mais diminuto o entendimento da internacionalização de empresas de pequeno e médio porte, com todos os condicionantes de recursos e competências que as caracterizam (RIALP et al., 2004). Neste artigo analisamos um caso de estudo de internacionalização de uma empresa de médio porte que se beneficia da inovação como fator determinante para a competitividade no mercado externo. Diante do exposto, o objetivo deste trabalho se constrói em analisar as estratégias de internacionalização de empresas como agente para promover a expansão internacional especificamente da empresa Prática Produtos S/A, bem como verificar sua trajetória até a entrada no mercado internacional e a utilização da inovação como fator competitivo. A inovação é importante para este processo, uma estratégia significativa visto que, com as rápidas mudanças no mercado e consumidores cada vez mais exigentes, a melhoria contínua nos processos se faz necessária.

Esta pesquisa de caracteriza como um estudo de caso aplicado na empresa Prática Produtos S/A, amparado por pesquisa bibliográfica, complementada por análise documental e entrevistas semiestruturadas com cinco gestores da empresa para ressaltar a importância da internacionalização e a contribuição da inovação neste processo. Os respondentes ocupam cargos estratégicos na empresa e são responsáveis pelas atividades de comercialização e exportação dos produtos fabricados; marketing e estratégias comerciais, sendo um dos respondentes sócio fundador da empresa. Os principais resultados indicam que a empresa iniciou suas atividades de internacionalização para buscar novos mercados, e consolidou suas atividades no exterior fundamentada por produtos com alto índice de inovação e competitividade e uma equipe de gestão preparada para absorver as oportunidades do setor. 
O artigo está organizado em quatro partes. Primeiro, apresentamos uma revisão teórica sobre internacionalização com enfoque no caso específico da internacionalização das multinacionais emergentes. $\mathrm{Na}$ segunda parte descrevemos os procedimentos metodológicos seguidos de uma apresentação histórica do lócus da pesquisa, essa descrição é relevante por considerar os principais fatos que conduziram a empresa ao processo de internacionalização. Na terceira parte relatamos os resultados da pesquisa. Concluímos com uma discussão alargada das práticas adotadas pela empresa para iniciar seu processo de internacionalização amparado por sugestões de pesquisas futuras.

\section{REVISÃO DA LITERATURA}

O estudo sobre o processo de internacionalização das empresas ganhou importância a partir da década de 70, com os trabalhos de Johanson e Wiedersheim-Paul (1975), Bilkey e Tesar (1977), Johanson e Vahlne (1977) no que ficou conhecido como a escola de Upsalla, onde se propunha que as empresas seguiam um processo gradual e incremental de internacionalização em dois vetores fundamentais: o modo de entrada e os mercados selecionados. A empresa segue uma escala crescente de envolvimento e comprometimento com um país estrangeiro, basicamente classificado em quatro ações: exportação não regular; exportação por representantes, estabelecimento de filiais de vendas e; unidades produtivas de fabricação no exterior. A escolha dos países ocorre basicamente por meio de análise da distância psíquica (diferenças culturais, idiomas, etc.); as empresas tendem a se internacionalizar para países que possuem menor distância psíquica do seu país de origem, facilitando assim as principais barreiras em países estrangeiros (JOHANSON, VAHLNE, 1977; JOHANSON, WIEDERSHEIM-PAUL, 1975).

Os estudos sobre internacionalização desenvolveram-se com os trabalhos de Dunning $(1980,1988$, 1994, 2003) sobre o paradigma Eclético. O paradigma Eclético, também conhecido por OLI - representando as iniciais de Ownership (Propriedade), Location (Localização) e Internalization (Internalização) - veio propor a análise de três vetores na decisão de internacionalização, especialmente da produção, pelas empresas. Efetivamente, as empresas necessitam possuir vantagens competitivas ou de "propriedade", ou seja, recursos que as tornem competitivas no mercado internacional, tais como o conhecimento e a tecnologia (STAL, 2010) vis-à-vis seus principais rivais, que elas utilizam para estabelecer produção em locais que são atrativos devido a suas vantagens de "localização" (CARNEIRO, DIB, 2007), sejam estas vantagens realizadas em elementos de custo ou de qualidade. E, que são melhor exploradas mantendo as operações no estrangeiro internalizadas. A internalização apresenta-se por comparação com as alternativas de serviço dos mercados externos, como a exportação ou o licenciamento, por exemplo.

Estas vantagens advêm da maior facilidade com a qual uma firma integrada pode apropriar retorno integral de sua propriedade de ativos distintivos como sua própria tecnologia, bem como da coordenação do uso de ativos complementares, que seriam os benefícios transacionais. (CARNEIRO, DIB, 2007). Muitas das dúvidas no processo de internacionalização podem ser consubstanciadas em cinco questões centrais: por que, o que, quando, onde e como as empresas internacionalizam (CUNHA, 2010; CARNEIRO, DIB, 2007). No entanto, como é o caso de grande parte das PMEs, a falta de recursos humanos e financeiros, de experiência internacional e de conhecimento dos próprios mercados externos e seus ambientes institucionais limita a sua internacionalização. Para superar estas deficiências, as PMEs brasileiras, podem formar redes 
de relacionamento, buscando agregar recursos de escala e escopo para superar tais limitações (AMAL et al, 2008). No entanto, as formas de parceria são relativamente pouco utilizadas, possivelmente pelas dificuldades de gerenciar relacionamentos e pelas próprias matrizes culturais.

\section{Por que internacionalizar: Motivações e benefícios}

As motivações estão relacionadas diretamente as aspirações de crescimento e vantagem competitiva das empresas. Fato esse consolidado pela estrutura e características das empresas e ações de investimentos adotadas. Existem muitos fatores de motivação, como o desejo de crescer e buscar novas oportunidades; marcar presença no mercado global, colocando-se próxima aos clientes; buscar economia de escala para reduzir custos; e a necessidade de competir e de estar entre os líderes do mercado (STAL, 2010). O aumento da competitividade no mercado doméstico em razão do aumento das importações favorecido pela abertura de mercado, força as empresas a achar alternativas que possibilitem a sobrevivência; então surge a necessidade da busca por novos mercados, desenvolvimento de conhecimento, romper as barreiras, utilizar a posição geográfica, fatores que impulsionam a empresa para inserção no mercado externo. A Figura 1 apresenta algumas motivações para a internacionalização, conforme a abordagem de Dunning (1994).

Figura 1: Motivações para internacionalização:

\begin{tabular}{|l|l|}
\hline \multicolumn{1}{|c|}{ Motivação } & \multicolumn{1}{c|}{ Significado } \\
\hline $\begin{array}{l}\text { Busca de recursos } \\
\text { (resource seeking) }\end{array}$ & Exploração de recursos naturais e vantagens em custo de, por exemplo, mão-de-obra. \\
\hline $\begin{array}{l}\text { Busca de mercado } \\
\text { (market seeking) }\end{array}$ & $\begin{array}{l}\text { Busca de vantagens de localização e sinergias de mercado, alargando a base de } \\
\text { potenciais clientes. }\end{array}$ \\
\hline $\begin{array}{l}\text { Busca de eficiência } \\
\text { (efficiency seeking) }\end{array}$ & $\begin{array}{l}\text { Busca de racionalização da produção, explorando economias de especialização e } \\
\text { localização, que permitem mais eficiência produtiva - elemento essencial em todas as } \\
\text { atividades e em especial em indústrias que seguem uma estratégia global. }\end{array}$ \\
\hline $\begin{array}{l}\text { Busca de recursos } \\
\text { estratégicos } \\
\text { (strategic resource seeking) }\end{array}$ & $\begin{array}{l}\text { Aquisição de recursos estratégicos seja em termos de competências ou no plano das } \\
\text { finanças, embora usualmente referido apenas pelo potencial de upgrade que as } \\
\text { operações no estrangeiro podem permitir ao aceder a novas tecnologias e } \\
\text { conhecimentos. }\end{array}$ \\
\hline
\end{tabular}

Fonte: Baseado em Dunning (1994).

Busca de recursos (resource seeking): nesta categoria, o objetivo principal das EMNs é o de adquirir tipos de recursos específicos que não estão disponíveis no seu mercado doméstico (como recursos naturais ou matérias-primas) ou que estão disponíveis a um custo menor (como mão de obra não qualificada que é oferecido a um preço mais barato em relação ao país de origem (FRANCO et al., 2010; DUNNING, 1994). O objetivo central é beneficiar os custos mais baixos no processo de produção (FERREIRA, SERRA, 2008).

Busca de mercado (market seeking): nesta categoria, as EMNs investem em um país estrangeiro para explorar as possibilidades oferecidas por mercados de dimensões maiores. Diversas razões (além da busca e exploração de novos mercados) levam a essa escolha das EMNs: seguir fornecedores ou clientes que construíram instalações de produção estrangeiras, adaptar bens às necessidades ou gostos locais e economizar o custo de servir um mercado de distância. Nos últimos tempos, está a tornar-se importante também ter uma presença física no mercado para desencorajar concorrentes potenciais de ocupar esse mercado (FRANCO et al., 2010; DUNNING, 1994). 
Busca de eficiência (efficiency seeking): nesta categoria, considera-se que ocorrem especialmente em duas ocasiões: No primeiro caso, as empresas "aproveitam as diferenças na disponibilidade e os custos das dotações tradicionais dos fatores em diferentes países", enquanto que no segundo "aproveitam as economias de escala e escopo e as diferenças nos gostos dos consumidores e as capacidades de oferta" (FRANCO et al., 2010; DUNNING, 1994). Este motivo pode ser caracterizado como identico ao de busca de recursos na medida em que as empresas dividem a produção de modo a beneficiar, por exemplo custos mais baixos de mão-de-obra em países menos desenvolvidos. (FERREIRA, SERRA, 2008).

Busca de recursos estratégicos (strategic resource seeking): esta última categoria de Dunning (1994) pode ser considerada separada porque, neste caso, o objetivo do investimento é adquirir e complementar uma nova base tecnológica, em vez de explorar os ativos existentes (FRANCO et al., 2010). As empresas realizam IDE com vista a adquirir novas competências e recursos, ou capacidades dinâmicas, em vez de se limitarem a explorar os ativos de que já dispõem Neste motivo não há intenção de explorar vantagens competitivas prévias, mas antes desenvolver novas vantagens. Ao realizar IDE, a empresa aceita um conhecimento específico a localizações (países, regiões ou mesmo cidades) receptoras ao aí sediar subsidiárias (FERREIRA et al, 2007; FERREIRA; SERRA, 2008; FERREIRA et al, 2009).

A busca por recursos, mercado e eficiência assentam na ideia de que a empresa se internacionaliza, eventualmente realizando IDE, porque pode realizar lucros adicionais ao explorar ativos específicos (FERREIRA et al, 2007). No entanto, firmas sem vantagens proprietárias sofisticadas permanecerão na etapa exportadora ou, no máximo, realizarão alguns investimentos externos para melhor comercializar a produção doméstica (DUNNING, 1988). Ou seja, é crucial a existência de alguma vantagem específica para encetar uma internacionalização mais ativa. Produzir no exterior exige vantagens de propriedade significativas, para vencer os custos de transação (STAL, 2010) e as desvantagens de ser estrangeiro (HYMER, 1976).

\section{Internacionalização de multinacionais emergentes}

O crescimento do fenômeno internacionalização de empresas em países emergentes se intensificou nos últimos anos (FERREIRA, et al., 2011a; STAL, OURA, 2009; FLEURY; FLEURY, 2007). Os países considerados emergentes são aqueles que apresentam grande potencial de crescimento do PIB, usualmente uma população abundante, e que têm buscado se reordenar em vários aspectos do mercado, e ambiente político e institucional. Alguns exemplos incluem os BRICS - Brasil, Rússia, Índia, China e África do Sul (FERREIRA, et al., 2011a), mas diferentes classificações incluem outros países como o México e Indonésia, por exemplo. Os mercados emergentes exigem, portanto, pesquisas e estudos específicos, uma vez que envolvem um grupo de países que tem vindo a ganhar um papel mais proeminente na economia internacional. No entanto, estes países têm características bastante heterogêneas devido aos próprios percursos históricos e a trajetórias culturais, políticas e étnicas (MELO et al., 2015). Em comum têm algumas deficiências institucionais ao nível das infraestruturas, educação, saúde e segurança, ambiente político e altos níveis de corrupção e informalidade, entre outras que geram dificuldades acrescidas nas transações (ROSOLEN, MACLENNAN, 2016; MELO et al., 2015, CUERVO-CAZURRA, HOLAN, SANZ, 2014; RAMAMURTI, 2012; FERREIRA et al., 2011a). 
Para Machado et al. (2016) o fator que mais contribui para o comportamento inicial da internacionalização das PMEs é a crença de seus gerentes de que o mercado-alvo é qualquer mercado, seja doméstico ou internacional. Para os executivos dessas empresas, o mercado, ao contrário das empresas internacionais graduais, é global. Pesquisadores como Hagen e Zuchela, (2014); Zhang, Tansuhaj, e McCullough, (2009); Leonidou, Katsikeas, e Piercy, (1998); Sousa, Martínez-López, e Coelho, (2008) perceberam que as atitudes gerenciais também influenciam as exportações de uma empresa, especialmente no caso das PME. Essas atitudes são geralmente identificadas como o comprometimento dos recursos organizacionais, promovido por seus gestores, para a atividade de exportação, ou seja, o comprometimento dos recursos de uma empresa com as exportações tem um impacto direto na velocidade de internacionalização e no desempenho global dessa empresa (MACHADO et al, 2016).

Recentemente houve um aumento significativo das exportações brasileiras, que passaram de US \$ 31,4 bilhões em 1990 para US \$ 242 bilhões em 2013 (MDIC, 2014; MACHADO et al, 2016). Além disso, $75 \%$ das empresas exportadoras brasileiras são micro, pequenas e médias empresas. Dessa forma, as PME brasileiras passaram por um novo contexto econômico e competitivo que, desde a década de 90 , vem sendo consistente com a ocorrência de PMEs que internacionalizaram de forma acelerada os estágios de "salto" do processo tradicional de internacionalização. As razões para esse comportamento estão relacionadas à homogeneização dos mercados globais e ao fato de que a internacionalização dos negócios agora se apresenta como uma estratégia-chave de muitas empresas (MACHADO et al, 2016).

As empresas se internacionalizam passando do processo de exportação para outros mais complexos, a fim de que os recursos e conhecimentos compartilhados no exterior sejam de propriedade exclusiva da empresa. Isso garante que as capacidades e recursos criados no estrangeiro se tornem competências essenciais da empresa (BORINI et al, 2006). A entrada de empresas de países emergentes por meio da aquisição de firmas em países desenvolvidos é uma estratégia que visa, principalmente, obter o conhecimento, a tecnologia e os canais de distribuição da empresa adquirida (STAL, 2010).

\section{MÉTODO}

Este estudo foi desenvolvido como estudo de caso da empresa Prática Produtos S/A. Amparado por pesquisa bibliográfica, optou-se por adotar o procedimento de pesquisa exploratória descritiva, com abordagem eminentemente qualitativa dado que se buscou identificar e analisar as principais práticas de internacionalização utilizadas pela empresa, com destaque a importância da inovação para inserção dos produtos no mercado internacional. Segundo Yin (2005), "o estudo de caso permite uma investigação para aprender as características significantes e holísticas de eventos da vida real - tais como, ciclos de vida individuais, processos organizacionais e administrativos, mudanças de vizinhanças, relações internacionais e a maturação de setores".

Para garantir a relevância nas informações coletadas em relação ao objetivo de investigação neste estudo, a empresa escolhida como objeto desta pesquisa foi selecionada mediante os seguintes critérios de seleção: (a) respeitar a classificação de pequena e média empresa considerando o indicador quantitativo de numero de funcionários estabelecido pelo SEBRAE/IBGE; (b) ter atividade comercial no exterior há mais de 2 anos; (c) disponibilidade para realizar entrevistas com gestores responsáveis pelas atividades de exportação 
e internacionalização da empresa, e ao menos um sócio fundador, que informem sobre as motivações, percepções e fatos ocorridos durante a internacionalização.

Estes elementos constituíram subsídios para a elaboração do roteiro semiestruturado para as entrevistas com cinco gestores, onde se focou especificamente a internacionalização e de onde ficou saliente a relevância da inovação para a internacionalização. As questões foram pré-selecionadas a fim de: (a) entender as motivações da empresa ao empreendedorismo, (b) escolha do setor de atividade e ações competitivas locais, (c) as principais iniciativas ao processo de internacionalização, (d) envolvimento de equipe gerencial e estratégica, (e) iniciativas competitivas e conhecimento técnico para instituir o processo de internacionalização. As questões foram colocadas de forma mais aberta permitindo aos respondentes descrever livremente o cenário em que os eventos foram ocorrendo ao longo da trajetória da empesa. Os respondentes ocupam cargos estratégicos na empresa, responsáveis pelas atividades de comercialização e exportação dos produtos fabricados; marketing e estratégias comerciais, um dos respondentes é sócio fundador da empresa. As entrevistas foram realizadas pessoalmente, gravadas e transcritas na integra, sendo que as informações utilizadas neste artigo foram resguardadas da identidade dos participantes. As entrevistas tiveram duração média de duas horas.

De acordo com Bardin (2002), o tratamento dos dados e a técnica da análise temática ou categórica utilizada foram baseados em operações de desmembramento do texto em unidades, e, posteriormente, organizando seu reagrupamento em classes ou categorias para melhor descrever os resultados. Além disso, a análise documental também está presente, para facilitar o manuseio das informações, já que, também de acordo com a autora, se constitui numa técnica que visa representar o conteúdo de um documento diferente de seu formato original, facilitando assim as consultas. Assim, a análise e interpretação dos resultados das entrevistas com os gestores da empresa Prática Produtos S/A foi abordada de forma qualitativa, para obter informações de como a empresa desenvolveu seu processo de internacionalização usando a inovação como vantagem competitiva.

\section{Caso em Estudo}

A Prática Produtos S/A, de Pouso Alegre no sul de Minas Gerais, iniciou com a união de dois irmãos em meados de 1991 com a fabricação de estantes de aço e prateleiras usadas em estabelecimentos comerciais e na fabricação de mata burros para atender as demandas das fazendas e prefeituras no interior do estado de Minas Gerais, mas viu se por parte dos gestores a necessidade de agregar valor aos produtos, inserindo tecnologia e design para estimular a competitividade no portfólio da empresa minimizando as estratégias comerciais que se resumiam a preço. A empresa atua desde 1995 na fabricação de fornos, estufas, máquinas para panificação e fornos combinados e atende os segmentos de panificadoras, supermercados, restaurantes comerciais (self service), buffets, alta gastronomia, restaurante a La Carte, fast food (Redes, Lanchonetes), hotelaria (Hotéis, Motéis, Pousadas), hospitais, pizzarias, concessionária de alimentos (catering, administradores de cozinha, restaurantes industriais), lojas de conveniência e indústria de congelados (PRATICA PRODUTOS S/A, 2016). 
A Prática Produtos S/A tem um perfil empreendedor e busca a melhoria contínua em seus processos de gestão, em prol de melhor qualidade e melhor utilização de recursos. Trabalhando dentro dos princípios da qualidade total em 2003, a empresa conquista a Certificação ISO 9001:2008. Em 2005 foi vencedora do Prêmio Excelência Empresarial SEBRAE - Gerdau. Em 2008, teve o apoio da Endeavor no que se refere à cultura empreendedora na busca de oportunidades e inovações para gerar empregos e renda. Em 2009, iniciou o programa Modelo de Excelência da Gestão (MEG) oferecido pela Fundação Nacional da Qualidade (FNQ) que favorece uma melhor gestão organizacional e planejamento estratégico em prol da busca por excelência. Em 2010 associou-se com a Embtech na busca por tecnologia e desenvolvimento. Participou do Prêmio Mineiro de Qualidade conquistando a faixa bronze em 2011, e faixa prata em 2013. A Prática Produtos SA foi reconhecida pela Revista Exame PME nos anos de 2006, 2007, 2008, 2009, 2011, 2012 e 2013 como a empresa que mais cresce no Brasil (PRATICA PRODUTOS S/A, 2016). A empresa conta com o BNDES como parceiro estratégico desde 2012 por oferecer financiamento para aquisição de equipamentos, obras civis, pesquisa e desenvolvimento de novos produtos (PRATICA PRODUTOS S/A, 2016).

A empresa acredita que seu maior diferencial competitivo seja o constante esforço de inovação e por esta razão tem estabelecido convênios com diversas entidades de pesquisa e tecnologia, tais como: Universidade Federal de Itajubá (UNIFEI) que realiza um estudo que visa melhorar a eficiência enérgica dos equipamentos; na Universidade Federal de Santa Catarina (UFSC) realiza um estudo de termossifão, referente a calor ou vapor. No Instituto Nacional de Telecomunicações (INATEL) é realizado um estudo das microondas e seu comportamento em local fechado e, na Universidade Federal de Ouro Preto (UFOP) onde é realizado um estudo relativo à nutrição destacando o trabalho horto molecular ao comparar a qualidade dos alimentos feitos em fornos convencionais e fornos combinados, ou seja, estas parcerias proporcionam melhoria contínua nos produtos oferecidos aos clientes e comprova sua qualidade e eficiência.

O processo de internacionalização da Prática Produtos S/A teve início em 2003, estimulado em 2004 quando aderiu ao programa Parceiros por Excelência (PAEX) da Fundação Dom Cabral, que tem como finalidade aumentar a competitividade, crescimento e busca por resultados. A excelência dos produtos Prática já é reconhecida no mercado internacional, sendo que atualmente a empresa exporta para 18 países em vários continentes. A Prática Produtos S/A adquiriu em 2006 a empresa Klimaquip ${ }^{1}$ a linha de refrigeração voltada para fabricação de ultra congeladores, já em 2009 fechou uma parceria internacional com o Grupo Mercatus e em 2010 inaugurou sua nova unidade fabril (KLIMAQUIP, 2014).

\footnotetext{
1 A Klimaquip é uma empresa brasileira, controlada pelo Grupo Mercatus, de Portugal, que atua especificamente no segmento de refrigeração como provedor de soluções em congelamento, resfriamento, aquecimento e estocagem de produtos alimentícios, seus equipamentos são produzidos com o que há de mais moderno, aliando tecnologia européia com custo brasileiro, produzindo equipamentos para verificação da hermeticidade dos sistemas frigoríficos, dosagem de gás refrigerante, conformidade e segurança dos sistemas elétricos.
} 


\section{RESULTADOS}

\section{Escolha do setor de atividade com enfoque nos produtos inovadores}

Uma das principais motivações para empreender na área industrial de panificação surgiu da percepção e experiência dos fundadores no setor de panificação. Esta afirmativa é relatada por um dos sócios fundadores respondentes da pesquisa quando diz que "a experiência familiar, voltada para o ramo de padarias constatou que a maior dificuldade encontrada era os gastos com energia elétrica que sobressaia sobre os outros custos. Nessa ótica surgiu a necessidade de buscar maior domínio tecnológico para obter alternativas de melhor utilização energética, assim a empresa iniciou a fabricação de fornos, estufas e máquinas para panificação em 1995 e fornos combinados a partir de 1997".

A gestora da área institucional e marketing da empresa Prática Produtos S/A relata que "seus concorrentes estão inseridos no mercado de gastronomia destacando a empresa Rational que comercializa produtos importados, já no mercado de panificação as empresas Perfecta e Bras Forno são tradicionais no ramo atuando há muito tempo no mercado". Para ser competitiva e superar a concorrência, a Prática Produtos S/A possui diferenciais ao nível da flexibilidade no processo de gestão operacional; que é uma vantagem comparativa já que tem como princípio a manufatura enxuta sendo o que há de melhor em termos de administração industrial, além de oito linhas de montagem, tem um setor de estamparia do estado de arte e uma área de usinagem bem equipada.

A preocupação na escolha do setor de atividade da empresa associado a visão estratégica dos gestores em fabricar produtos de qualidade e inovação tecnológica superior, potencializou a competitividade da empresa neste segmento de mercado, favorecendo assim a comercialização e inserção de suas atividades no mercado nacional e internacional.

\section{Aspirações para internacionalização}

A empresa visualizou na exportação uma nova oportunidade, que levou a Prática Produtos S/A em 2003 ser reconhecida internacionalmente. O gestor responsável pela área de exportação da empresa indicou que "no ano de 2011 a exportação representava 5\% do seu faturamento total. Atualmente, exporta para mais de 18 países, ocupa 90\% do mercado da América Latina, tendo como mercados potenciais: Chile, Colômbia e Equador. Para divulgação de seus produtos no mercado externo a empresa, desde 2007, participa de feiras e eventos internacionais nos Estados Unidos, Europa e América Latina".

Predomina então a visão da Prática Produtos S/A de ser uma empresa de classe mundial e atuação global, atingindo excelência reconhecida em serviços ao cliente, produtos, processos produtivos e sistemas administrativos.

Para representar sua marca no mercado internacional, a empresa possui acordo com joint ventures e com representantes na Argentina, Bolívia, Chile, Colômbia, Equador, México, Paraguai, Peru, Uruguai e Venezuela. Estes representantes responsabilizam-se pelas vendas e pelo pós-venda. Para manter a competência e eficiência deste trabalho internacional, é oferecido anualmente um encontro técnico para aprimoramento do conhecimento dos produtos e inovações ocorridas; cada representante possui material de 
apoio, como suporte aos representantes internacionais, a empresa conta um representante na cidade São Paulo/SP responsável pelos representantes internacionais da América Latina e um gerente de assistência técnica internacional.

\section{Da exportação ao investimento em aquisições}

Embora a internacionalização por exportação seja o modo de entrada nos mercados externos mais simples, de menor risco e com menor necessidade de investimento, o que o torna o mais adequado para empresas em fases iniciais da sua internacionalização, mesmo a exportação apresenta alguns desafios para empresas ainda inexperientes. Conforme relatado pelo gestor internacional, a Prática Produtos SA deparouse com dificuldades em aspetos como uma taxa cambial para exportação elevada; produtos importados da China com qualidade inferior e com custo baixo; legislação do país de destino, exigências de certificações e declarações; custos com logística, despreparo dos órgãos brasileiros; tratamento fito sanitário, e por último a dificuldade de encontrar profissionais com o domínio de idiomas, sendo que para atenuar este problema foi realizada uma ação corretiva onde colaboradores, com funções chaves relacionadas a negociações internacionais, têm aula de inglês. A Prática Produtos S/A em 2006 realizou uma fusão com o Grupo Português Mercatus adquirindo parte da Klimaquip, empresa pertencente ao grupo, com intuito de aumentar as vendas nacionais, obter uma troca de tecnologias e desenvolver produtos de alto design na linha de refrigeração e ultra congeladores. Foi constatado com os gestores que a empresa conta com o apoio de diversas instituições importantes neste processo de internacionalização, tendo como principais parceiros: Associação Brasileira das Indústrias de Equipamentos para Panificação (ABIEPAN), Associação Brasileira da Indústria de Máquinas e Equipamentos (ABIMAQ), Agência Brasileira de Promoção de Exportações e Investimentos (APEX), Associações de classes, Banco Nacional de Desenvolvimento Econômico e Social (BNDES), Federação das Indústrias, Ministérios do Desenvolvimento, Indústria e Comércio Exterior (MDIC) e Ministério de Relações Exteriores; este apoio fortalece o crescimento no mercado internacional e consequentemente o crescimento econômico do Brasil.

Para compreender esta necessidade de adentrar no mercado externo, o gestor internacional da Prática Produtos S/A relatou os benefícios encontrados neste novo empreendimento tais como: "localização geográfica nas transações com países da América Latina e as alianças políticas entre os mercados como o Mercado Comum do Sul (MERCOSUL) e Associação Latino-americana de Integração (ALADI) que favorecem o livre comércio e a política comercial internacional, promovendo o desenvolvimento econômico dos países envolvidos e o crescimento das empresas no mercado internacional".

Os gestores da empresa afirmam que "a Prática Produtos S/A crescerá muito, para isso há um planejamento e houve a criação do Plano Prática 2015, elaborado através de uma parceria com um estudante de MBA da Harvard Business School, para aprimorar as técnicas de identificação das necessidades dos clientes e mapear a evolução futura dos mercados. Com este planejamento a empresa visa ser 10 (dez) vezes maior que em 2008 e 2009 a nível nacional e internacional até 2015. No mercado internacional, tem como estratégia de crescimento aumentar a intensidade na América Latina, desenvolver o mercado norte americano com a possibilidade de abertura de um escritório comercial nos Estados Unidos e no futuro investir na Europa". 
Assim, pode-se dizer que, a Prática Produtos S/A visualiza o crescimento internacional como algo que ocorre ao longo do tempo, usa a exportação como forma de internacionalização, este é o início que oferece menores riscos. Com um planejamento minucioso, que envolve pesquisa, adéqua suas estratégias às mudanças que ocorrem no mercado, prevalece como fator competitivo a inovação nos produtos, que tem como principal diferencial a preocupação com a eficiência energética e qualidade dos alimentos preparados em seus produtos. Valoriza, acima de tudo, seus colaboradores e seus clientes, fonte de recursos para seu crescimento contínuo; contudo, no mercado internacional, possui os requisitos e apoio necessários para continuar crescendo e obter destaque entre as empresas brasileiras que estão inseridas no mercado externo.

\section{Reconhecimento da equipe comercial}

Um dos gestores reforça que "a Prática Produtos S/A valoriza muito o trabalho desempenhado pelos representantes internacionais. Estes representantes possuem domínio do idioma e da cultura do país em que estão instalados facilitando a comunicação. Em alguns mercados são exclusivos da marca, ou seja, apenas representam a empresa Prática Produtos S/A, mas esta situação oscila de mercado para mercado, atuam de forma estratégica no mercado onde estão inseridos, tendo como maior dificuldade no relacionamento com os representantes internacionais a legislação e a política dos países da América Latina que são distintas da política brasileira". O gestor da Prática Produtos S/A chama atenção para a realização do Projeto Comprador, que em 2006 reuniu representantes internacionais para apresentação dos produtos e a cada dois anos realizam uma convenção de vendas com representantes nacionais e internacionais.

Os representantes internacionais aplicam suas competências técnicas e comerciais nos países em que a empresa atua, estreitando barreiras e empecilhos na comercialização dos produtos, estando mais próximos dos clientes para responder de imediato às necessidades e solicitações pontuadas. Um dos sócios fundadores respondentes da pesquisa reforça que "ter escritórios de representação nos países de interesse comercial e uma equipe comercial comprometida e preparada tecnicamente facilita as atividades de internacionalização da Prática Produtos S/A".

\section{Inovações para a internacionalização}

É fundamental destacar a produção de fornos com eficiência energética que é uma vantagem competitiva em relação aos seus concorrentes. Para manter este diferencial, a Prática Produtos S/A mantém parcerias com instituições de ensino como: UNIFEI, UFSC, INATEL e UFOP, que através de P\&D inovam cada vez mais o desempenho e design dos produtos oferecidos no mercado atendendo às necessidades de seus clientes. Cabe destacar que esta evolução vai ao encontro com os conceitos citados por Breen e Hamel, "em um mundo de descontinuidade, o que mais importa não é a vantagem competitiva de uma empresa em um único momento, mas sua vantagem evolucionária ao longo do tempo" (2007, p. 99).

O caso da Prática Produtos SA encontra alguns paralelos em casos bem conhecidos de empresas de economias emergentes de sucesso na internacionalização. A Prática Produtos, tal como algumas destas multinacionais emergentes já se internacionalizam baseadas no aumento de sua produtividade e nos resultados de esforços de inovação que têm vindo a realizar. Por exemplo, A empresa WEG iniciou seu 
processo de internacionalização em 1971 e no momento está presente em mais de 100 países. A sua estratégia foi orientada por quatro pontos principais: i) o fortalecimento da marca no Brasil e no exterior, objetivando garantir a fidelidade dos clientes; ii) internacionalização com atuação em todo o mundo, focada na ampliação para economias do Oriente (China e Índia), na busca por maiores escalas de produção na série de produtos e na constituição de novas unidades fabris e expansão da rede de distribuição internacional; iii) inovação tecnológica: investimento sucessivo em P\&D e intensificação dos programas de padronização de produtos e métodos; e, iv) aumento da rede de assistência pós-venda em nível mundial (BNDES, 2008).

Já a empresa Votorantim começou a crescer no âmbito internacional com o objetivo de diversificar suas receitas e defender a sua posição no mercado interno, diante da possível entrada de concorrentes, pois grande parte da produção mundial de cimentos está concentrada em cinco empresas. No entanto, começou tarde seu processo de internacionalização e, considerando que a atuação com diversificação geográfica, em que custos de frete e logísticos são fundamentais na formação do preço final do produto, a inserção no mercado externo foi essencial para o crescimento da empresa (BNDES, 2008). Os investimentos no exterior foram através de instalações de escritórios, com o objetivo de estar mais próximo dos clientes e evitar a intermediação por tradings. A empresa está presente em países da Ásia, da Europa e nos Estados Unidos, possui uma fábrica no Canadá e um escritório na Argentina (IEDI, 2010).

Reconhece-se a importância das parcerias que a empresa possui para desenvolver produtos com maior qualidade e diferencial aos seus clientes, com essa enorme capacidade de inovação é possível ser competitivo nos países de destino e sobreviver no país de origem. Diante do contexto apresentado pela empresa analisada, fica claro, conforme aborda Barbieri et al., ao afirmar que "no âmbito externo a decisão de inovar é uma condição essencial para que a empresa consiga ganhar mercados internacionais e atender os rígidos padrões desses mercados" (2004, p. 31). Reconhece-se que a internacionalização fortalece as marcas nacionais e cria um importante diferencial de mercado em um mundo cada vez mais competitivo.

\section{DISCUSSÃO E CONSIDERAÇÕES FINAIS}

Neste estudo buscou-se utilizar alguns construtos fundacionais à literatura de negócios internacionais e em especial os orientadores da internacionalização de empresas para analisar a internacionalização de uma média empresa brasileira.

A empresa Prática Produtos S/A, analisada através de uma pesquisa aplicada com seus gestores, iniciou seu processo de internacionalização em razão da busca de mercado para obter maior crescimento e atingir maiores resultados. Um elemento crucial para a capacidade competitiva nacional e internacional é o investimento em pesquisa e desenvolvimento (P\&D) em tecnologias e processos de fabricação dos produtos. A P\&D também permite que a Prática Produtos S/A agregue diferenciais aos seus produtos. A empresa desde 1999 utiliza ferramentas, programas e desenvolve parcerias na área de qualidade para agregar valor aos seus produtos e em 2003 conquistou a certificação ISO 9001:2000 na busca por excelência e melhoria continua em seus processos. Esta trajetória confirma os conceitos voltados ao empreendedor, conforme citado por Hitt et al. "empreendedorismo significa fazer algo novo, diferente, mudar a situação atual e buscar, de forma incessante, novas oportunidades de negócio, tendo como foco a inovação e a criação de valor" (2008). 
Os investimentos destinados à capacitação dos profissionais tornam a organização mais preparada para atender às novas exigências. A Prática Produtos S/A em 2006 realizou uma fusão com o Grupo Português Mercatus adquirindo parte da Klimaquip, empresa pertencente ao grupo, com intuito de aumentar as vendas nacionais, obter uma troca de tecnologias e desenvolver produtos de alto design na linha de refrigeração e ultra congeladores. Esta proposta vai ao encontro do conceituado por Hitt, et al. (2008 p. 247) "uma aliança estratégica é uma estratégia de cooperação em que as empresas combinam alguns de seus recursos e capacitações para criar uma vantagem competitiva".

É interessante ressaltar que as empresas brasileiras envolvidas há algum tempo com a internacionalização tem destaque internacional em razão de desenvolver produtos diferenciados, com maior qualidade, maior tecnologia e inovação, por visualizar novas oportunidades em mercados que envolvem sustentabilidade e que agregam valor econômico e social. Contudo a Prática Produtos S/A possui sua tecnologia voltada para produção de equipamentos com eficiência energética e que mantenham a qualidade dos alimentos, possui um planejamento em médio prazo que visualiza seu crescimento no mercado internacional nos próximos anos, possui profissionais qualificados e seu conhecimento é baseado em investimentos em P\&D o que proporciona inúmeras inovações em seus produtos, isto torna a empresa competitiva e atrativa, estes fatores agregam valor à estrutura organizacional e fazem com que esteja apta a enfrentar o mercado internacional e suas constantes mudanças o que interfere em suas estratégias que sofrem adequações para que a empresa consiga atingir seus objetivos.

\section{Limitações e pesquisas futuras}

A pesquisa foi realizada por meio de um estudo de caso, com entrevistas junto aos principais gestores da empresa. Como é comumente reconhecido o método do estudo de caso tem a limitação de dificuldade de generalização para uma população mais alargada. É possível que este seja o espaço para outros estudos, talvez multi-caso, explorando experiências e dificuldades de pequenas e médias empresas. Em especial será interessante focara empresas que buscam a internacionalização partindo de países que, como as economias emergentes, têm um conjunto de ineficiências institucionais. Ou seja, analisando como as ineficiências institucionais no mercado doméstico buscam e forçam as empresas a prosseguir estratégias alternativas para a sua expansão nos mercados externos. Estes estudos podem ter uma contribuição efetiva para a prática gerencial, mas, também, para a teoria ao explorar como os fatores de localização e as vantagens específicas às multinacionais emergentes podem contribuir para a internacionalização.

Os dados coletados em 2011 representam um momento de expansão da empresa no processo de internacionalização, basicamente com inserção dos produtos no mercado externo por meio de exportação e escritórios de representação no exterior, fato este que justifica a realização deste estudo, porém, muitas outras atividades foram desenvolvidas nos últimos 5 anos pela empresa. Entender os estágios de consolidação e ampliação das atividades de internacionalização permitirá realizar estudos comparativos e evolutivos da empresa neste aspecto.

Estudos em PMEs são importantes para o debate nos âmbitos acadêmico e organizacional, esse setor tem representatividade significativa na economia nacional, sendo caracterizado por diversas singularidades. O processo de internacionalização em PMEs é caracterizado no período inicial pela busca de novos mercados 
por meio da exportação. Trazer luz a esta temática favorece pesquisadores a se interessarem e ampliarem os estudos de internacionalização nas PMEs. Como sugestão de pesquisas futuras, seria relevante entender as motivações dos gestores em internacionalizar que excedem o âmbito de competitividade, as parcerias que favorecem o processo de internacionalização com ênfase nas redes relacionais estabelecidas.

\section{Considerações finais}

Este artigo tem como principal objetivo apresentar as motivações de uma PME para iniciar seu processo de internacionalização, que se beneficiou da inovação para entrar competitivamente no mercado externo. Este estudo confirma os preceitos teóricos de que a inovação facilita a entrada de empresas no mercado externo. Fica evidente também que a atuação dos gestores com comportamento visionário e uma equipe comprometida e alinhada aos propósitos da empresa favorece o processo de internacionalização. Para a prática organizacional, esta pesquisa traz luz a outras empresas que desejam internacionalizar, pois apresenta as principais ações de entrada de uma PME que explora novos mercados com excelência na fabricação de seus produtos e atuação dos gestores, a fim de entender a dinâmica do setor de atuação no mercado externo.

\section{REFERÊNCIAS}

ALEM, A.; CAVALCANTI, C. BNDES e o apoio à internacionalização das empresas Brasileiras: Algumas reflexões. REVISTA DO BNDES, 12(24), p. 43-76, 2005.

ALMEIDA, A. (Org.); CYRINO, A.; ALEM, A.; CAVALCANTI, C.; TRAVESSO NETO, D.; PENIDO, E.; ALMEIDA, F.; BARRETO, F.; SAUVANT, K.; VALENTE, M.; MUNHOZ, M.; MELLO, M.; ANTUNES, P.; REZENDE, P.; RICUPERO, R.; CRETOIU, S.; PINHEIRO, T. Internacionalização de empresas brasileiras. Rio de Janeiro, RJ: Editora Elsevier, 2007.

AMAL, M.; FREITAG FILHO, A.; MIRANDA, C. Algumas evidências sobre o papel das redes de relacionamento e empreendedorismo na internacionalização das pequenas e médias empresas. Revista de Administração FACES,7(1), p. 63-80, 2008.

BANCO NACIONAL DE DESENVOLVIMENTO ECONÔMICO E SOCIAL - (BNDES). Relatório anual 2008: Internacionalização. Rio de Janeiro, 2008. Disponível em:<http://www.bndes.gov.br >. Acesso em: 20 mai. 2016.

BARBIERI, J. (Org.). Organizações inovadoras: Estudos e casos brasileiros. 2ed, Rio de Janeiro, RJ: FGV, 2004.

BARDIN, L. Análise de conteúdo. Lisboa: Edições 70, 2002.

BARTLETT, C.; GHOSHAL, S. Going global: Lessons from late movers. Harvard Business Review, 78(2), p. 133-142, 2000.

BREEN, B.; HAMEL, G. O futuro da administração. Rio de Janeiro, RJ: Campus, 2007.

BILKEY, J.; TESAR, G. The export behavior of smaller Wisconsin manufacturing firms. Journal of International Business Studies, 9(1), p. 93-8, 1977.

BORINI, F.; RIBEIRO, F.; COELHO, F.; PROENÇA, E. O prisma da internacionalização: Um estudo de caso. Revista de Administração FACES, 5(3), p.42-55, 2006.

BUCKLEY, P.; CASSON, M. The internalization theory of the multinational enterprise: A review of the progress of a research agenda after 30 years. Journal of International Business Studies, 40(9), p. 1563-1580, 2009.

CARNEIRO, J.; DIB, L. A. Avaliação comparativa do escopo descritivo e explanatório dos principais modelos de internacionalização de empresas. Internext - Revista de Negócios Internacionais da ESPM, 2(1), p. 26-39. 2007.

CUERVO-CAZURRA, A., HOLAN, P.; SANZ, L. Location advantage: Emergent and guided co-evolutions. Journal of Business Research, 67(4), p. 508-515, 2014.

CUNHA, S. Processo de internacionalização de uma empresa multinacional brasileira de base tecnológica. Revista de Administração FACES, 9(4), p. 67-84, 2010. 
DUNNING, J. Toward an eclectic theory of international production: some empirical tests. Journal of International Business Studies, 11(1), p. 9-31, 1980.

DUNNING, J. The eclectic paradigm of international production: a restatement and some possible extensions. Journal of International Business Studies, 19(1), p. 1-31, 1988.

DUNNING, J. Re-evaluating the benefits of foreign direct investment. Transnational Corporations; 3(1), p. 23-51, 1994.

DUNNING, J. Some antecedents of internalization theory. Journal of International Business Studies, 34(2), p. 108-115, 2003.

FERREIRA, M.; LI, S.; LOPES, M.; SERRA, F. Cross-border acquisitions of foreign firms in Portugal and of Portuguese firms abroad: Exploration and exploitation through acquisitions. Economia Global e Gestão, 12(1), p. 125-147, 2007.

FERREIRA, M.; SERRA, F. Foreign entry modes under institutional pressures: The impact of strategic resource seeking and market seeking strategies. Revista de Ciências da Administração, 10, (22), p. 11-29, 2008.

FERREIRA, M.; LI, D.; JANG, Y. Foreign entry strategies: Strategic adaptation to the various facets of the institutional environments. Development and Society, 38(1), p. 27-55, 2009.

FERREIRA, M.; REIS, N.; SERRA, F. Negócios internacionais e internacionalização para as economias emergentes. Lisboa: Lidel, $2011 \mathrm{a}$.

FERREIRA, M.; SERRA, F.; REIS, N. On the adaptation of the firm's strategies to the International Business Environment: A knowledge-based and evolutionary perspective. European Journal of International Management, 5(6), p. 633-655, 2011b.

FLEURY, A.; FLEURY, M. Internacionalização e os países emergentes. São Paulo, SP: Editora Atlas, 2007.

FRANCO, C.; RENTOCCHINI, F.; VITTUCCI G. Why do firms invest abroad? An analysis of the motives underlying foreign direct investments. The ICFAI University Journal of International Business Law, 9(1-2), 42-65. 2010.

GALLINA, R.; BULBA, E. A.; FLEURY, A. O processo de internacionalização de uma empresa brasileira de setor de autopeças: O caso Sabó. XI Seminário Latino-lberoamericano de Gestión Tecnológica, Salvador: ALTEC, 2005.

GOMES, G.; SILVEIRA, A.; AMAL, M. Internacionalização de pequenas e médias empresas em periódicos de administração com alto fator de impacto: 2000-2008. Revista Ibero-Americana de Estratégia, 9(3), 112-138, 2010.

GOVINDAN, K.; KANNAN, D.; SHANKAR, K. Evaluating the drivers of corporate social responsibility in the mining industry with multi-criteria approach: A multi-stakeholder perspective. Journal of Cleaner Production, 84(2), 214-232, 2014.

HAGEN, B.; ZUCHELA, Z. Born global or born to run? The long term growth of born global firms. Management International Review, 54(4), p. 497-525, 2014.

HILAL, A.; HEMAIS, C. A. Da escola de Uppsala à escola Nórdica de negócios internacionais: uma revisão analítica. In: ENANPAD - Encontro Anual da Associação Nacional dos Programas de Pós-Graduação em Administração (Anais do Congresso). Campinas-SP, 2001.

HYMER, S. The International Operations of National Firms: A Study of Foreign Direct Investment, Cambridge, MLT Press. 1976.

HITT, M., IRELAND, R., DHOSKISSON, R. Administração estratégica. 2ed, São Paulo, SP: Thompson Pioneira, 2008.

INSTITUTO DE ESTUDOS PARA O DESENVOLVIMENTO INDUSTRIAL (IEDI). O investimento estrangeiro na economia brasileira e o investimento de empresas brasileiras no exterior. Disponível em: <www.iedi.org.br>. Acessado em: 18 fev. 2016.

JOHANSON, J.; WIEDERSHEIM-PAUL, F. The internationalization of the firm: Four Swedish cases. Journal Management Studies. 12(3), p. 305-323, 1975.

JOHANSON, J.; VAHLNE, J. The internationalization process of the firm: A model of knowledge and increasing foreign market commitment. Journal of International Business Studies, 8(1), p. 23-32, 1977.

KLIMAQUIP. Nossa empresa. Disponível em: <http://www.klimaquip.com.br/a-empresa.php> Acesso em: 25/09/2014.

LE BAS, C.; SIERRA, C. Location versus home country advantages in R\&D activities: Some further results on multinationals locational strategies. Research and Policy, 31(2), p. 589-609, 2002.

LEONIDOU, L.; KATSIKEAS, C.; PIERCY, N. Identifying managerial influences on exporting: Past research and future directions. Journal of International Marketing, 6(2), p. 74-102, 1998.

MACHADO, M.; NIQUE, W.; FEHSE, F. International orientation and export commitment in fast small and medium size firms internationalization: Scales validation and implications for the Brazilian case. Revista de Administração, 51(3), p. 255-265, 2016.

MDIC - Ministério do Desenvolvimento, Industria e Comércio Exterior. (2014). Disponível em http://www.mdic.gov.br. Acesso em 10/12/2016. 
MELO, P.; BORINI, F.; OLIVEIRA JR., M.; PARENTE, R. Internationalization of Brazilian Franchise chains: A comparative study. Revista de Administração de Empresas, 55(3), p. 258-272, 2015.

PRÁTICA PRODUTOS S/A. Relatório de Gestão. Disponível em: www.praticafornos.com.br Acesso em: 15/07/2016.

RAMAMURTI, R. What is really different about emerging market multinationals? Global Strategy Journal, 2(1), p. 41-47, 2012.

RIALP, A.; RIALP, J.; KNIGHT, G. The phenomenon of early internationalizing firms: what do we know after a decade (1993-2003) of scientific inquiry? International Business Review, 14(2), p. 147-166, 2004.

ROSOLEN, T.; MACLENNAN, M. Strategic human resource management and corporate social responsibility: Evidence from Emerging Markets. Internext - Revista eletrônica de negócios internacionais - Review of international business, 11(2), p. 66-80. 2016.

SOUSA, C.; MARTINEZ-LOPES, F.; COELHO, F. The determinants of export performance: A review of the research in the literature between 1998 and 2005. International Journal of Management Reviews, 10(4), p. 343-374, 2008.

STAL, E.; OURA, M. Internacionalização e competitividade de empresas fabricantes de café torrado e/ou moído: 0 impacto do Projeto Setorial Integrado de promoção de exportações de café. In Anais do SIMPOI - Simpósio de Administração da Produção, Logística e Operações Internacionais, São Paulo, SP, 2009.

STAL, E. Internacionalização de empresas brasileiras e o papel da inovação na construção de vantagens competitivas. Revista de Administração e Inovação, 7(3), p. 120-149, 2010.

SZAPIRO, M.; ANDRADE, M. Internacionalização em arranjos e sistemas de MPME - NT1.8. In: LASTRES, M.; CASSIOLATO, J.; SZAPIRO, M.; ALBAGLI, S.; LEGEY, L.; LEMOS, C. Proposições de políticas para a promoção de sistemas produtivos locais de micro, pequenas e médias empresas. Rede de sistemas produtivos e inovativos locais. Universidade Federal do Rio de Janeiro, Rio de Janeiro, 2001.

YIN, R. Estudo de caso: Planejamento e métodos. 3ed,. Porto Alegre, RS: Bookman, 2005.

ZHANG, M.; TANSUHAJ, P.; McCULLOUGH, J. International entrepreneurial capability: The measurement and a comparison between born global firms and traditional exporters in China. Journal of International Entrepreneurship, 7(4), p. 292-322, 2009. 